\title{
Independent living with mobility restrictions: older people's perceptions of their out-of-home mobility
}

\author{
Henna Luoma-Halkola* (D) and Liisa Häikiö \\ Faculty of Social Sciences, Tampere University, Tampere, Finland \\ ${ }^{\star}$ Corresponding author. Email: henna.luoma-halkola@tuni.fi
}

(Accepted 15 June 2020; first published online 20 July 2020)

\begin{abstract}
We studied older people's perceptions of how they organise their out-of-home mobility and independent living when they face mobility restrictions, based on seven focus groups with older people $(\mathrm{N}=28)$ from a suburb in Finland. This article provides an everyday life view of how the ability to move outside the home evolves through interdependencies between older people and their neighbourhoods, social relations and societal arrangements. Our findings show that supportive socio-material surroundings can provide older people with new ways to move outside their home despite mobility restrictions and new ways to organise their daily life with decreased mobility. In contrast, restrictive socio-material surroundings can lead to situations in which older people forgo certain out-of-home journeys and activities. The findings contribute to an understanding that organising one's daily life and out-of-home mobility is an act of interdependence. Policies promoting independent living in old age should recognise these fundamental interdependencies and support versatile ways of living rather than overemphasise activity and self-reliance. Based on older people's everyday life perspectives, both sides of the coin need to be considered: how to enable the out-of-home mobility of older people facing mobility restrictions and how to support them in managing and enjoying daily life with decreased mobility.
\end{abstract}

Keywords: out-of-home mobility; mobility; interdependence; independent living; older people

\section{Introduction}

An Ageing in Place policy framework is the major response to population ageing in many European countries. The aim is to promote the independent living of older people in their own homes and living environments for as long as possible (e.g. Kröger and Bagnato, 2017). This policy has led to practices that appreciate older people's independence and activity and to an increasing number of older people living at own home with mobility restrictions and care needs. As the prevalence of mobility difficulties, frailty and disability increases with age (Shumway-Cook

(c) The Author(s), 2020. Published by Cambridge University Press. This is an Open Access article, distributed under the terms of the Creative Commons Attribution licence (http://creativecommons.org/licenses/by/4.0/), which permits unrestricted re-use, distribution, and reproduction in any medium, provided the original work is properly cited. 
et al., 2005; Gale et al., 2014), ageing may lead to reduced out-of-home mobility (Smith et al., 2016). This is a major challenge for the ideal of independent living, as it is important for both individuals and societies that older people are able to move outside their homes to take care of daily errands and access services and amenities. For individuals, moving outside the home also provides possibilities to enjoy social encounters with other people and enjoy the outside world (Musselwhite and Haddad, 2010; Musselwhite, 2017; Graham et al., 2020).

This paper discusses the complicated connections between out-of-home mobility restrictions and independent living. We study how older people organise their out-of-home mobility when they face mobility restrictions and act in accordance with them. To address older people's views on living and moving in the city, we conducted seven focus groups with older residents $(\mathrm{N}=28)$ from a Finnish suburb. Their accounts of organising out-of-home mobility when facing mobility restrictions involve many types of journeys and activities in relation to manifold contextual aspects. Based on their perceptions, out-of-home mobility evolves through interdependencies between older people and their social networks, built and natural environments, seasonal and weather conditions, transportation services, societal rules and norms, and finances. In some situations, older people have agency in creating and adopting new ways to organise their out-of-home mobility and their daily lives; in other situations, constraining circumstances can lead to mobility loss.

The findings contribute to the understanding that organising one's daily life and out-of-home mobility is an act of interdependence (Portacolone, 2011; Schwanen and Ziegler, 2011; Coleman et al., 2016). This involves recognising the interdependence with other humans and non-humans as an inevitable part of human life. Thus, independence is fundamentally a 'collective achievement', not the result of individuals' self-reliance (Reindal, 1999; Schwanen and Ziegler, 2011: 723). This paper provides an everyday life perspective on the study of the interdependencies of out-of-home mobility as part of organising independent living in old age. Independent living for older people with mobility restrictions poses a challenge not only for older persons but also for their social networks and the families that support these individuals in their homes, as well as for societies that need to develop services and environments to enable the out-of-home activities and journeys of older individuals who face mobility restrictions.

We begin by conceptualising out-of-home mobility and interdependence and their mutual relationship in the context of old age. We discuss previous research on how the opportunities to move about outside the home are created by an interaction between older individuals and their socio-material surroundings. Second, we introduce the research context and methods, involving a thematic analysis of focus groups with older people living in a Finnish suburb. Third, we outline our empirical findings regarding how older people organise their out-of-home mobility and daily life. Finally, we conclude by discussing out-of-home mobility as an act of interdependence and provide implications for future research and policy.

\section{Out-of-home mobility and interdependence in later life}

In this study, out-of-home mobility refers to the ability to physically move outside the home. This involves both journeys from one destination to another using 
various modes of mobility (i.e. walking, using a wheelchair, using public transport, driving a car) and activities such as gardening or gym training (Mollenkopf et al., 2004, 2011; Mollenkopf, 2005). In the context of everyday life, these two aspects of mobility are highly intertwined (Ziegler and Schwanen, 2011). Qualitative studies indicate that older people interpret both aspects as fundamentals of living. Mobility is about independence, wellbeing and freedom, as well as getting things done (Goins et al., 2015).

The prevalence of mobility difficulties, frailty and disability increases with age (Shumway-Cook et al., 2005; Wilkie et al., 2006; Gale et al., 2014). Thus, for some older people, ageing implies declining mobility (Smith et al., 2016) and lower satisfaction with opportunities to journey and participate in activities outside the home (Mollenkopf et al., 2011). Assisted mobility can enable older people 'to continue participation in life as they have known it' (Goins et al., 2015: 939). Although some older people welcome assistive devices and readjust their daily lives, others have difficulties accepting their mobility loss and refuse assistance due to their fear of dependence (King et al., 2011; Goins et al., 2015). The fear of dependence may reflect the pervasive imperative for independence and selfreliance in our contemporary individualistic societies, which can make it difficult for older people to accept assistance when they face difficulties in their daily lives. Thus, dependence has a negative connotation of being a burden to others and not fulfilling the ideal of individual autonomy or activity (Portacolone, 2011).

Previous research entails different understandings of independence in old age. Especially in health sciences, individualistic understandings that emphasise an individual's capacities and self-reliance prevail (Plath, 2008). These individualistic notions of independence essentially denote 'the absence or avoidance of reliance on others' (Secker et al., 2003: 378). In contrast to these understandings, scholars in the fields of social work (Plath, 2008), social gerontology (Portacolone, 2011), geography (Schwanen and Ziegler, 2011; Schwanen et al., 2012), disability studies (Reindal, 1999), health promotion (Secker et al., 2003) and feminist studies of care (Collopy, 1995) have promoted more complex understandings of independence in later life. Studies that have explored older individuals' own perceptions of independence in Western individualistic societies have shown that the meanings of independence are manifold and changing (Plath, 2008; Portacolone, 2011; Schwanen et al., 2012). While individualistic understandings in terms of self-reliance prevail among older people, they also construct their independence in relation to various resources, such as services, finances and other people, as well as in relation to their role within their social networks. For some, independence also signifies the ability to make decisions regarding their daily lives (Plath, 2008). Moreover, older people have varying perceptions of what independence means in relation to their mobility. For some, assistive devices signify dependence, whereas for others, they signify independence and emancipation, implying that some older people understand independence in terms of interdependence (Portacolone, 2011). Previous research also suggests that assistive devices and transportation services may be more easily viewed as independent ways of moving, while seeking assistance from other people is perceived as being dependent and burdensome (Schwanen et al., 2012).

To oppose the negative connotations of dependence and celebration of independence, some scholars have advocated reframing 'dependence' as a normal 
feature of human life rather than an occasional nuisance (Fine and Glendinning, 2005; Schwanen et al., 2012). They have shown that these inevitable dependencies of human life occur in reciprocal care relationships that connect people together (Fine and Glendinning, 2005) and in individuals' relationships with other humans and non-humans in their daily lives (Schwanen et al., 2012). To overcome the distinction between independence and dependence altogether, Reindal (1999: 364) has called for acknowledging 'the human condition as one of interdependence'. This view involves recognising that independence is 'a collective achievement' or 'a partnership', as all individuals are fundamentally dependent on other people, their living environments and societies (Reindal, 1999: 364; Schwanen and Ziegler, 2011: 723). The notion of interdependence entails a relational understanding of the subject embedded in a certain context (Reindal, 1999). Drawing from this perspective, we explored how older persons depend or rely on their socio-material surroundings when they organise their daily lives and out-of-home mobility.

In practice, ageing in place requires supportive relationships for organising mobility when impairments reduce an older person's possibilities to journey and participate in activities outside the home. In these situations, interdependencies with social networks are needed to maintain one's home and everyday life (Coleman et al., 2016). Social relationships shape older people's out-of-home mobility in many ways; other people can assist in moving outside the home (Schwanen et al., 2012; Nordbakke, 2013), although caring for a family member can restrict opportunities for travel (Mollenkopf et al., 2011). Independence and mobility are also conditional on personal and bodily abilities and various materialities, such as technologies, infrastructures and finances (Schwanen et al., 2012). Built urban contexts with differing traffic infrastructure, land use and amenities shape the opportunities for out-of-home mobility (Föbker and Grotz, 2006; Rosso et al., 2011). A supportive environment increases older people's likelihood of going out and environmental barriers decrease it (Clarke and Gallagher, 2013). For example, poor sidewalk quality, slopes, lack of benches and short street-crossing times pose mobility barriers in later life (Wennberg et al., 2009; Rosenberg et al., 2013; Rantakokko et al., 2015). Moreover, the natural environment shapes out-of-home mobility in old age. Blue and green spaces motivate older people to go outside (Finlay et al., 2015), while poor weather conditions, such as ice and snow, are associated with restricted out-of-home mobility (Rantakokko et al., 2015; Clarke et al., 2017). Therefore, the ability to organise out-of-home mobility and daily life involves the interdependence of older people with their socio-material surroundings (Portacolone, 2011; Schwanen and Ziegler, 2011; Coleman et al., 2016).

A large share of previous research on out-of-home mobility was focused on the built environment, while fewer studies have explored the interactions between different contextual aspects of mobility, such as the built and natural environment, policies, legislation, social relations, finances and cultural norms (Schwanen and Páez, 2010; Webber et al., 2010; Franke et al., 2020). In line with these ideas, Green et al. (2014) have shown how the use of public transport is culturally, materially and politically context-specific. Their site of research, London, has an extensive public transport infrastructure, and the use of public transport is a common part of urban life. London also has a policy that provides free public travel for older 
persons. In this context, the authors show that older persons experience bus travel as an act of belonging in the city. For older persons, bus travel involves meaningful social encounters but also struggles. Moreover, cultural norms regarding 'old age' shape older persons' experiences of bus travel. While some older people enjoy being offered a seat, some dislike being identified as 'old'. Considering this interplay between manifold contextual aspects, we scrutinise how out-of-home mobility takes place in relation to versatile contextual aspects in older people's everyday lives.

In addition, older individuals' personal features, situations, perceptions and life biographies shape their ability to move outside the home (Webber et al., 2010; Franke et al., 2020). Older people with functional limitations perceive environmental barriers as more significant than those without limitations, and the importance of barriers increases with age (Wennberg et al., 2009). The environment facilitates and restricts walking outside the home differently for older people using mobility devices than those who do not use them (Clarke, 2014; Hallgrimsdottir and Ståhl, 2018), and for older people with varying levels of lower-body function in terms of balance, muscle strength and walking speed (Satariano et al., 2016). Older age, severe mobility restrictions and fear of falling constitute risk factors for not going out (Smith et al., 2016). Gender and socio-economic status are also connected to out-of-home mobility, as being female and having a low income and education increase the risk of severe mobility limitation (Shumway-Cook et al., 2005). Thus, older people constitute a heterogeneous group of people with different ages, perceptions, situations and conditions, implying that some older people are more vulnerable to environmental barriers than others.

To provide an everyday life account of the interdependencies of out-of-home mobility, it is vital to examine older people's perceptions of various out-of-home activities and journeys in relation to a wide variety of contextual aspects (Schwanen and Páez, 2010; Webber et al., 2010; Franke et al., 2020). Drawing from the notion of interdependence (Reindal, 1999; Schwanen and Ziegler, 2011), we scrutinise how older persons facing mobility restrictions rely on their socio-material contexts when they organise their daily lives and out-of-home mobility.

\section{Context: a suburban area in Finland}

To study older people's perceptions of organising out-of-home mobility when facing mobility restrictions, we selected a suburb of the Finnish city of Tampere. Finland has an ageing society. The percentage of people over 65 years of age is 22.3 per cent (in 2019) and is expected to increase to 26.3 per cent by 2030 (Official Statistics of Finland, nd), and the majority are expected to live in urban regions. The Tampere region is the second most important in Finland in terms of population and economic activities; the metropolitan area of Helsinki is the first. The selected area, Hervanta, is the largest suburb of Tampere, with approximately 25,000 residents and a high population of older residents $(16 \%$ are over 65 years old). In Hervanta, the mean annual income $(€ 19,900)$ is lower than that in the city of Tampere $(€ 27,500)$. Hervanta is also the most multicultural suburb of Tampere, with 20.7 per cent of the residents speaking a foreign language as their native language (City of Tampere, nd; Official Statistics of Finland, nd). 
Hervanta was one of the first suburban areas in Finland, built in the 1970s and 1980s. Many of those who moved there at that time are now ageing there. The idea of independent living in one's own home profoundly impacts Finnish ageing policies and elder-care arrangements (Anttonen and Häikiö, 2011). Although many responsibilities of ageing in place fall on individuals and their families, public authorities have the legal responsibility to organise health and social services and support older people's independent living, health and functional capacity. ${ }^{1}$ Many municipalities, including Tampere, provide dial-a-ride door-to-door transport for people with mobility restrictions as part of the public transport system. Older people with disabilities may also be entitled to special transport services (taxi services) based on the Social Welfare Act ${ }^{2}$ or Act on Disability Services and Assistance. ${ }^{3}$

Hervanta has been a test bed for national policies on age-friendly cities (20132017) within the World Health Organization's Global Age-friendly Cities approach. Hervanta represents a high-density suburb with good walking routes, efficient public transport, and versatile public and private services with easy access. Hervanta is surrounded by forest and lakes, which intertwine with the built environment. As the area was mainly built in the 1970s, many residential buildings pose mobility barriers. Some apartment buildings do not have elevators or accessible entrances. Socially, Hervanta is an active suburb and several volunteer organisations provide assistance and leisure activities for older residents. Building on these features, the Age-friendly Hervanta project (2015-2017) focused on out-of-home mobility, developed housing and the built environment, and enhanced the inclusion and participation of older residents (Moisio and Savolainen-Korjus, 2018). It concretely developed accessible walking routes to connect daily services with their housing.

\section{Methods: thematic analysis of focus group data}

In co-operation with the Age-friendly Hervanta project and two community centres for older people, we facilitated seven focus groups with older people in Hervanta during the spring and summer of 2017. One of the centres was supported by the city of Tampere and the smaller centre by a volunteer organisation. Before conducting the focus groups, we participated in the meetings and activities organised in one of the community centres and walked around the suburb to observe and photograph a variety of habitual places in Hervanta by ourselves. We also organised two multi-professional workshops to understand social and material barriers to participation in later life.

Participants were largely recruited through the community centres, which forwarded the information to a few volunteer organisations. Moreover, an advertisement for the focus groups was published in a free local newspaper, which is delivered to almost all households in the suburb. Advertisements were also delivered to a local library, health centre and pharmacy.

We reached 28 older persons ( 19 women, nine men), and some of them participated more than once. After accounting for multiple participations, the total number of participants was found to be 43 . They consisted of a heterogeneous group of Finnish pensioners of different ages and life situations. Some were in good health whereas others had mobility impairments and various health conditions. Some participants used assistive mobility devices, including wheelchairs or 
walkers. Some participants lived in a senior home, and others lived alone or with their spouse in an apartment, terraced house or detached house.

The aim of the focus groups was to explore living in Hervanta from older people's perspectives. Three focus groups engaged in general discussions about everyday living in the suburb and four of them had more specific themes: (a) services, (b) housing, (c) leisure activities, and (d) nature. The themes were not strict, and participants could talk very freely about important things in their lives. The aim was to elicit discussion among the participants while the facilitator stayed more in the background (see Morgan, 2001). Photographs of the suburb were utilised to elicit memories of suburban locations and create alternative ways for participants to express their experiences (Clark-Ibáñez, 2004). The focus groups entailed discussions of participants' personal experiences of living in the suburb and the widely shared views of Hervanta being a good place to live. The focus groups ranged from one and a half hours to two hours and were audio-recorded and transcribed.

We carefully followed the ethical guidelines of the Finnish National Board on Research Integrity (TENK, nd), respecting the autonomy and privacy of participants and avoiding harm. Participation was voluntary and based on informed consent; we informed the participants about the purposes and implementation of the research, how the data would be used and the rights of the participants. After ensuring that participants had understood the information, we asked them to sign a letter of consent. To secure the anonymity of participants, we use pseudonyms when reporting our findings.

We conducted a thematic analysis following the guidelines of Nowell et al. (2017). In the first phase, we familiarised ourselves with the data by reading it multiple times and then coded the data with Atlas.ti software. The coding involved systematically identifying situations in which older people with physical or cognitive functional limitations faced mobility restrictions regarding journeys from one destination to another or activities such as gardening or picking berries.

In these situations, functional limitations included a wide range of issues such as back, knee and hip problems, lack of energy, sciatica, Parkinson's disease, memory disorder and heart disease. Sometimes participants described their condition vaguely: 'The last few years I've mostly spent being ill.' Most of the identified situations included explicit accounts of functional limitations, and few entailed an implicit understanding of some kind of functional limitation (i.e. using a taxi service for disabled persons). The identified situations included discussions of actualised mobility or the potential for mobility. Actualised mobility refers to situations in which participants with physical or cognitive functional limitations moved outside their home. Potential for mobility refers to situations in which participants considered their opportunities of moving with functional limitations.

During the second phase, the identified situations were grouped inductively into three themes, which were carefully reviewed and refined by both authors: (a) new mobility patterns, (b) independent living with reduced mobility, and (c) restricted situations. These themes were grouped according to the ways in which participants organised their out-of-home mobility when they faced mobility restrictions and by how relations between older people and their socio-material surroundings supported or restricted out-of-home mobility. In the course of analysis, it became evident that in older people's view the issue concerns organising independent living 
more generally. Drawing from the notion of interdependence (Reindal, 1999; Schwanen and Ziegler, 2011), the findings provide an everyday life understanding of how older people with physical or cognitive functional limitations depend or rely on their socio-material surroundings when they organise their daily life and out-of-home mobility.

\section{Findings}

Focus group participants shared that they had faced mobility restrictions in relation to personal health problems and a wide variety of contextual aspects. These included poor weather conditions, long walking distances, hills, loss of local services, construction projects, illness of a spouse, as well as institutional elderly care and health-care settings. In response to varied mobility restrictions, older people organised their out-of-home mobility and daily lives in different ways. We first scrutinise how older people adopt new mobility patterns relying on public transport services and rehabilitation and recreational services. Second, we focus on how older people organise independent living with reduced mobility relying on their social networks and proximity to local services. Third, we discuss restricted situations in which older people forgo certain out-of-home journeys and activities due to constraining circumstances.

\section{New mobility patterns: supportive services}

Focus group participants perceived that supportive public services had created opportunities to move around outside the home when they faced mobility restrictions. Special transport services provided means to access local services, and rehabilitation and recreational services offered ways to improve or maintain functional capacity. These public services enabled older people to continue to go to places, take care of themselves and their daily responsibilities, and make independent choices in their lives despite mobility constraints.

When older people faced mobility restrictions, their ability to organise out-ofhome mobility and continue daily activities as usual depended most importantly on public transport services. Participants collectively valued Hervanta as a good place to live because transport services were well organised there. A dial-a-ride door-to-door service enabled participants to run errands, maintain their habitual living environment and continue living in their home when they faced mobility restrictions:

Eija: If I just stayed healthy, I'd enjoy life so much now, and I'd not leave Hervanta. Things are so well organised here...

Martta: Everything.

Eija: $\quad$...like shopping and things for those who can't move about so well. They pick you up and drop you off at your doorstep, carry your bags to the lift and press the button for you.

Martta: Yes, exactly.

Eija: $\quad$ Nowhere else is as well organised as here.

Jaakko: Dial-a-ride buses take you back and forth. 
Aino: Without the dial-a-ride buses, we couldn't live in our detached house. Martta: So you always call for it to get you.

Jaakko: Yes, because we don't have a car these days, so the dial-a-ride bus is really important.

Aino: When Jaakko got ill, the car went.

Jaakko: The car went, and my licence went. (Focus group 2)

For participants, the dial-a-ride door-to-door bus was a positive way to organise journeys for daily activities when they were unable to walk or use a private car due to health problems, poor weather conditions or involuntary loss of a driver's licence. These positive perceptions are in line with previous research that has shown that older people tend to perceive public transport as independent mobility, illustrating how they enact independence through dependencies on transport technologies (Schwanen et al., 2012). Participants valued the door-to-door service more than other transportation solutions:

Irja: I think the dial-a-ride bus is the best service anyone has invented that allows old and frail people to get around like other people and take care of their own affairs.

Ritva: Yes, it's good because you can't get on a normal bus with your walker, can you? You can't lift it.

Sinikka: No, it's pretty difficult.

Ritva: And when you're not in good shape, they get you from your doorstep and take you all the way there. (Focus group 7)

Participants relied on the door-to-door service rather than on regular buses, as mobility impairments and assistive devices made it difficult to use regular public transport. In practice, this meant that participants' possibilities to complete daily errands were dependent on the limits created by the operating principles of the service:

Sinikka: It's [the dial-a-ride bus] really good, but I'm a bit annoyed that the time that it runs is a bit too short, for when you can use it.

Keijo: It could leave at four as well.

Sinikka: That's right. And on weekends and so on, so that we could get some sort of service like that at other times too.

Irja: $\quad$ Yes, so you could get somewhere on the weekend too. [...]

Ritva: And the bus is always full.

Sinikka: Yes, that too. There should be more of them. [...]

Keijo: $\quad$ Everyone is trying to get to the $2 \mathrm{pm}$ bus because if they can use the bus card even a minute before $2 \mathrm{pm}$, then they only pay half price.

Sinikka: Oh yes, it is the senior discount. (Focus group 7)

There was a policy in place that allowed older people to receive a senior discount on public transport between 9 am and $2 \mathrm{pm}$. Some older people timed their journeys so that they could receive the discount, while some had the financial means to avoid 
the peak time at $2 \mathrm{pm}$ and take a later bus. The dial-a-ride bus only ran during Finnish office hours and within a limited geographical service area in Hervanta. As journeys are inseparably interconnected with other activities of daily living (Ziegler and Schwanen, 2011), these operating principles have consequences on where and when one can do things.

New mobility patterns also emerged in relation to public rehabilitation and recreational services to maintain or improve personal functional capacity with declining health. One participant discussed a gym group she had participated in. It was important for her that the gym group provided her with suitable equipment and a social environment and was free of charge. Her perceptions also reflect how new opportunities for physical activity had evolved in relation to a changing policy environment and cultural norms regarding what kind of people go to gyms:

Me and Ritva have been in this group organised by the city called Strength in Old Age in the physiotherapy ward of the health centre. Twelve gym sessions for old people like us. I think the minimum age limit is 75 . And it's free, this rehabilitation for old people. It's really great ... It's the city's, but you can't just turn up there. You have to get a physiotherapist's referral. They decide who needs the rehabilitation. There's probably loads of groups, but in the last few years, there's been groups for old people, which is really good I think, that 70-80-year-olds go there. Lots of rowing and thigh benches, and you stay fit for longer. Then, you need less care. They never used to send 80-year-olds to the gym. I don't know how long they've been doing it because when I came to Hervanta, nothing like this would even have been talked about, arranging gym sessions for old people ... There are some private gyms here too, but the city's gym is upstairs in the health centre. It's not like the ones for those men, who lift weights and that, but there's a rowing machine and things like that, which you do while sitting, and then, old people can do it too. I said it's a really good thing ... And they cost, those private ones, don't they cost quite a lot? (Irja, Focus Group 7)

The participant's perception reflected the wider policy discourse, which placed the responsibility of one's wellbeing on older individuals themselves rather than on public authorities - a shift that had taken place in Finland since the 1990s (Jolanki, 2009; Anttonen and Häikiö, 2011). The gym group that was mentioned in the excerpt was part of a national Strength in Old Age Programme that had been operating since 2010. The aim was to enhance the independent living and wellbeing of older people through physical exercise (Age Institute, nd). As part of the Ageing in Place policy, older people were expected to actively take care of their health and gyms had increasingly become places for older people.

New mobility patterns emerged as older people faced with mobility restrictions organised their out-of-home mobility with dependence on assistive devices, weather conditions, finances, social norms and available public services and transport infrastructure. Public transport and rehabilitation services provided opportunities for being active and moving outside the home despite mobility restrictions. These interdependencies were produced in relation to the wider policy framework through which the public authorities 'enable and create such conditions that make it possible for older people to be responsible for their own welfare' and for 
independent living at home (Anttonen and Häikiö, 2011: 73), creating new opportunities but also moral obligations for being mobile and active.

\section{Independent living with reduced mobility: supportive services and social relations}

Older participants discussed situations in which they were no longer able to cope with certain out-of-home activities or journeys by themselves. Based on their perceptions, assistance from other people and the proximity of services created opportunities to organise daily life so that one did not have to move so much. Previous research has shown that older age and a decline in physical functioning are associated with a reduced living environment (Portegijs et al., 2014) and fewer trips outside the home (Su and Bell, 2009). In general, older people tend to utilise services close to their homes rather than travel longer distances (Engels and Liu, 2013). Hence, supportive socio-material surroundings can also create opportunities to manage and enjoy daily life with reduced mobility.

Many participants depended on the proximity of local services to support their daily lives when they faced mobility restrictions. They appreciated Hervanta as a good place for older people with mobility difficulties, as the centre had a wide range of private and public services within a small radius close to the residential areas. One participant shared how she faced difficulties accessing local services when her health declined. Hence, she moved to a senior house closer to services, changing the set of interdependencies into more supportive ones that enabled her to manage her daily life with less mobility:

Mostly, the move was because here they had a neighbourhood centre, arranged by the city, and there still is too, just in a different form. And it had all sorts of things. We could get massages, pedicures, we had a hairdresser, and you could eat lunch here every day. And my health got so bad that it was really difficult to get about. And from there [old apartment], at that time, there were none of these dial-a-ride buses like now, and there was no bus that went along my street which took you to the centre. So, it was really hard to always go by foot to the shopping centre, bank, post office, and shop because I could hardly walk. And I thought that this new apartment would be a bit closer to the shopping centre and this house itself had services, and I've never regretted it. This is a really wonderful place. (Irja, Focus Group 6)

Some participants relied on assistance from their social networks for gardening and completing daily errands when health problems or loss of local services created mobility restrictions. Thus, social networks supported older people's independent living and created freedom to make choices in their living arrangements:

Maire: I can't do anything at the cottage anymore, gardening and things. The children go there, or one really, my youngest daughter always goes there and gets the place in order...

Aino: We also have a grandchild who comes to do the heaviest work, and we need to get him to come again and turn the compost.

Maire: Do you have a cottage somewhere then? 
Jaakko: No, we have a detached house. We manage little by little, there's always something to do to keep us moving about.

Maire: Yes, there is. That's what my husband liked too. In a detached house, he always had something to tinker with.

Aino: I'd be ready to give up, but Jaakko won't leave, 'I'm never leaving my home' (laughs).

Jaakko: But moving is always such hard work, so where would you go?

Aino: He's afraid of moving. (Focus Group 2)

The participants relied primarily on assistance from their children and grandchildren, which is common in Finland, where it is usually the close social circles who undertake care responsibilities of their loved ones, not the wider networks (Anttonen and Häikiö, 2011). The participants appreciated the practical help they received. Previous research conducted in Finland has indicated that while some older people perceived assistance positively (Tuominen and Pirhonen, 2019), others expressed the negative perceptions of being a burden, reflecting the wider societal discourses that promoted self-reliance in old age (Jolanki, 2009). On the other hand, some older people understood their independence in terms of being able to make decisions over their daily lives - not merely as the ability to manage daily activities unaided (Pirhonen et al., 2016). Thus, reliance on social networks in later life is a complicated issue shaped by societal discourses and older persons' versatile perceptions.

Some participants also perceived their out-of-home mobility in relation to socialising. When long physical distances and health problems create mobility restrictions, it may become valuable to have opportunities to enjoy meaningful social encounters with significant others in proximity. One participant shared that physical encounters with her sister were dependent on her sister making the journey:

I have a sister who's about 70, older than me. We talk every now and then because we live in different towns and I don't travel anymore because of my health, but my sister is in better shape and she can travel longer distances than me so... Then, when we meet, we always talk about our childhood days and our youth. It's really great, we remember all the people who were in our childhood environment. (Leila, Focus Group 1)

Supportive socio-material surroundings can enable older people to manage and enjoy their daily lives with less mobility and to make decisions about their living arrangements when they face mobility restrictions. These interdependencies are formed in relation to elderly care policies, which have increasingly placed the responsibility of older people's welfare and independent living on families and social networks (Kröger and Leinonen, 2012). In addition, our findings indicate that older people can sometimes change the set of interdependencies and create new opportunities to manage out-of-home mobility and daily life, e.g. by moving to a more supportive residential area. Similarly, previous research has suggested that older people can change their contextual conditions by opting for activities closer to home or choosing more accessible routes and destinations (Nordbakke, 2013). 


\section{Restricted situations: mobility barriers}

Older people had also faced restricted opportunities to organise out-of-home mobility, which led them to forgo certain out-of-home activities and journeys. These situations were perceived as being largely determined by the constraining circumstances regarding health problems, social relations, and built and natural environments, as well as societal institutions, including institutional elderly care and health care.

Many older participants perceived their restricted mobility in relation to a decline in their health, which shaped their relationship with their surroundings. Consequently, they were unable to take part in certain out-of-home journeys and activities. Many of these were outdoor and winter activities, such as cross-country skiing, sledding, picking berries in the forest or enjoying the lakeside. Many participants talked fondly about these past activities and shared how health problems had changed their relationship with nature:

Researcher: I would like to ask a little bit more. Do you spend time in nature?

Keijo: $\quad$ Yes, I did. Just over ten years ago, I regularly went around a nearby lake, but now I can't go anymore. I'm not really up to it because of my condition. It has such big hills.

Toivo: I went around its shores too and sometimes skied. The ski route is a bit, the hill is ... I've really skied down the hill a lot, it's not half as dangerous going down it in cross-country skis when you can't turn anywhere but just keep going along the tracks. In the end, I skied another route because it was more even there. It's a bit too hilly for old people, that one downhill route is.

Sinikka: It's a hilly place, Hervanta. (Focus Group 7)

Older people also perceived their restricted mobility in relation to their built neighbourhoods, which were shaped by changing seasons, weather conditions and construction projects. Participants discussed difficulties walking outdoors when there was snow, which is in line with previous research (Clarke et al., 2017; Rantakokko et al., 2015). In Finland, the winter can last for half a year, and from pedestrians' perspective, the maintenance of walkways is sometimes too slow and inadequate (Aavajoki, 2012). Moreover, older people's neighbourhoods were also shaped by the ongoing tramline construction, which was about to impede the door-to-door transportation (taxi service for persons with disabilities) of one participant who was dependent on it:

Helmi: $\quad$ So, now we're supposed to get a tramline here.

Researcher: Yes, that's coming too.

Maria: Unfortunately.

Helmi: $\quad$ Yes.

Inkeri: They'll break up the whole town.

Helmi: It'll be on the edge of the street. Just last Thursday when we were in the wheelchair taxi, the driver asked, 'Which route shall I take to get you home if this street is closed?' I was like, well, there you have a problem, you'll have to carry me home (laughs). You won't get your taxi into my yard. (Focus Group 1) 
These construction sites were common in Tampere. The city was making investments to attract new residents and to meet the needs of an increasing population. Even though construction projects were a temporary phase, for the very old, they could last even for the rest of their lives, creating difficulties for out-of-home mobility.

Older people also discussed their mobility restrictions in relation to their social worlds. Some participants told how being a part of an ageing social group meant giving up shared excursions to various activities, as many people had died or had poor mobility. In addition, one participant described his restricted mobility in relation to his changed family situation. His wife had clearly been an important source of support enabling their shared living in their own home; after she became ill, the participant was placed in a care home. There, he faced institutional rules restricting his out-of-home mobility and self-determination:

Eino: $\quad$ So, my wife had to go to hospital. The geriatrician said in this meeting we had that this man is not to live alone. So, they took me to the care home. I was there for a week and half. It got so cramped there that they moved me here [another care home]. So, here I am ... The same geriatrician also said, 'You can't drive a car anymore.' Well, I won't drive. I gave my car to my grandchildren. [...]

I think I'd been here two days when a woman dressed in outdoor clothes with a bag knocked on my door and said 'I'm a voluntary worker. Do you want to go for a walk?' And that's how it began. Three times I went there with a kind of chaperone. After that, it was a bit freer and I was able to walk there alone.

Researcher: So, you couldn't at first?

Eino: $\quad$ Not at first, and normally here you can't, all the doors are locked. You have to get a nurse to open the door and tell the nurse that you're going and about what time you come back so that they know. And then they've bought these security wristband things for all of us, so that we can send an alarm, and we have a clock and a diary. (Focus Group 5)

Thus, one could lose a driver's licence or be placed in a care home if one's condition was perceived as a safety risk to oneself or others based on legislation and healthcare professionals' evaluation. Moreover, commonly shared practices and norms in the care culture shape the opportunities for out-of-home mobility in institutional settings. Nurses making decisions on physical restraint as part of their daily work feel conflicted: they feel that restraints improve older persons' safety but feel guilt over the negative mental and physical consequences of restraint for older persons (Saarnio and Isola, 2010). These practices constitute balancing between risk management and an older person's independence. Whereas some care homes exercise tight control to avoid risks, some support residents' autonomy by allowing them to engage in potentially risky activities, while minimising the risks. Older people themselves perceive the ability to retain control over their 
lives in care settings as highly important (Bland, 1999). Institutional care settings entail a complicated contradiction between an older person's self-determination and safety.

The relationship between societal rules and older individuals' out-of-home mobility was reflected in one participant's inability to have a dog due to difficulties with picking up the faeces. Cleaning pet faeces in public places is a legal (and normative) duty in Finland, except for the assistance dogs of people with disabilities. ${ }^{4}$ These kinds of societal rules can create surprising difficulties for older people:

Anna: $\quad$ So many new houses have been built here, I don't get about much there anymore. I don't have a dog anymore. I've been without a dog for a year because it was put down, so I said I won't get another dog because I'm nearly 90 and I can't pick up dog poo. I'll fall flat on my face soon ... The children brought me a cat then.

Researcher: Well I was just about to suggest why not a cat.

Anna: $\quad$ Yes. The cat turned 16 years yesterday. But it comes always so fast from the toilet and its paws spread sand all over the floor. (Focus Group 3)

After the participant's dog died, her children brought her an old cat. The participant said that she preferred dogs over cats. The inability to have a dog was a great loss, and the participant spoke fondly about the past adventures with her deceased dogs involving encounters with animals and people.

One participant perceived her restricted mobility in relation to inadequate public health care she had received when she faced health problems. Due to sudden health problems, she had given up meaningful leisure activities:

Researcher 1: How have the opportunities for leisure time activities changed here in Hervanta in the time you've lived here?

Researcher 2: A perspective of about 20 years, eh?

Emma: Well, I can't really generalise, but I was really involved in everything and there was really nice things to do and be part of. My health has been bad now for two years, so I don't know what it's like now. Nature probably thought that at the end of last winter I should have kicked the bucket, but because I went to the emergency room and cried and cursed, I got help. I got a pacemaker, and it works ... They didn't take care of me very well. And it seems this is not the first, there's many here, you talk to people about how this is a bit ... you don't really get help. You have to be really determined.

Researcher 1: Yes, health care.

Emma: $\quad$ Yes, that's why I don't know how this has all changed now. I've been out of sorts for two years ... and then, I got this back and this leg and I can't get around much. (Focus Group 5)

The participant described her inability to participate in leisure activities due to health problems and poor health care. This is in line with previous research, 
which has shown that older people perceive adequate health and social care as important for their ability to remain independent and to continue going to places, participate in meaningful activities and meet other people (Tiilikainen et al., 2019).

Older participants perceived their mobility restrictions in relation to health problems, natural and built environments, social networks, and institutional elderly care and health-care settings. Consequently, older people had given up out-ofhome journeys and activities such as enjoying nature, walking a dog and other meaningful leisure activities. Similarly, previous research has shown that sometimes older people prioritise necessary daily errands over leisure activities when their health declines (Franke et al., 2017). Previous research also suggested that mobility decrease in old age is not always voluntary, as older people with mobility difficulties are less satisfied with their out-of-home mobility than those with no difficulties (Mollenkopf et al., 2002, 2011). Thus, older people may not always fulfil the ideals of activity promoted by societal discourses and practices. According to previous research, older people display different kinds of feelings and attitudes towards mobility loss. While some perceive mobility loss as an inevitable part of ageing and accept it, others perceive it as unacceptable and devastating (King et al., 2011). Hence, restrictive circumstances can sometimes lead to negative consequences on out-of-home mobility in later life.

\section{Discussion}

Based on a thematic analysis of focus groups with older people from a suburb in Finland, we studied how older people living independently organise their out-of-home mobility when they face mobility restrictions and act in accordance with them. The findings contribute to an understanding that organising one's daily life and out-of-home mobility is an act of interdependence, as the ability to move about outside the home depends on social and societal arrangements, and material surroundings in the day-to-day context of older people. Based on older people's perceptions, interdependencies with supportive socio-material surroundings can provide new ways to organise out-of-home mobility and daily life, despite restrictions. In contrast, constraining circumstances can lead older people to forgo certain journeys and activities. Sometimes older individuals can also change the set of interdependencies influencing their out-of-home mobility through their own actions, e.g. by moving to a more supportive residential area. Hence, out-of-home mobility is essentially a 'collective achievement' that takes place in the interdependence of older people with their social and material worlds (Schwanen and Ziegler, 2011; Schwanen et al., 2012).

Our study contributes to the previous literature on out-of-home mobility in old age by providing an everyday life perspective of older people's interdependencies with their socio-material surroundings in organising out-of-home mobility as part of their independent living. First, available resources such as public transport, rehabilitation services and social networks are critical in organising out-of-home mobility and daily life. These interdependencies are produced in relation to the wider policy context in Finland, where social policies have increasingly shifted the responsibility of older people's welfare from public authorities to older individuals and their social networks (Anttonen and Häikiö, 2011; Kröger and Leinonen, 
2012). This shift is visible in the policy discourses, which have promoted active and self-reliant subject positions for older individuals (Anttonen and Häikiö, 2011) that have been linked with the rise of neoliberalism in other Western societies, such as the United Kingdom and the United States of America (Portacolone, 2011; Schwanen and Ziegler, 2011). Regarding practices, the increasing number of older people ageing in their own homes has been coupled with a decreasing share of public home care services (Kröger and Leinonen, 2012). Consequently, many older persons experience unmet care needs in their activities of daily living, including out-of-home journeys and activities (Kröger et al., 2019). Thus, out-of-home mobility and independent living take place in complex relations between older individuals and local social policies that shape older persons' subject positions and responsibilities.

In our study, the dial-a-ride door-to-door service was found to support the independent living of older people. Nevertheless, the bus schedules and zones created boundaries to where and when they could go. These constraints could restrict older persons' opportunities to fulfil their mobility needs if they were dependent on the service, especially in terms of spontaneous and discretionary travel (Musselwhite and Haddad, 2010; Musselwhite, 2017). Moreover, some older people timed their travel so that they could receive the senior discount between 9 am and 2 pm. Similarly, previous research has suggested that some older people prioritise their out-of-home journeys based on affordability ( $\mathrm{Su}, 2007$; Franke et al., 2019), indicating the importance of finances for out-of-home mobility in old age. Therefore, the interdependence of older people with the local public transport infrastructure can create both opportunities and constraints for out-of-home mobility and shape its temporalities. More studies are needed to explore the temporal aspects of older persons' out-of-home mobility further, as it is an underresearched area (Franke et al., 2020). To support independent living of older people facing mobility restrictions, there is a need to consider how the planning of schedules, zones and fees for public transport could provide flexibility in terms of when and where they can go - like other people.

As part of independent living, some participants had given up certain meaningful leisure activities. Many of these were winter and nature activities in which they were no longer able to partake. In Finland, cross-country skiing, ice skating and sledding are common out-of-home activities and an integral part of the cultural heritage. Finns become accustomed to these activities in primary schools (Sievänen and Neuvonen, 2010; Landauer et al., 2013), and they are enabled by long snowy winters. Similarly, many nature activities, such as picking berries and mushrooms in the forest, are common in Finland, which has numerous forests and lakes. Additionally, the 'Everyman's rights' provide the legal right for everyone to enjoy nature for recreational purposes-regardless of who owns the land (Sievänen and Neuvonen, 2010). These out-of-home activities are shaped by the relations between the local climate, nature, culture and legislation. To support the meaningful independent living of older people, there is a need to develop supportive nature areas that enable older people to continue enjoying nature despite mobility restrictions. This is important because access to the natural environment is associated with wellbeing (Capaldi et al., 2015) and green and blue spaces motivate older people to go outside (Finlay et al., 2015). 
Our findings also show that it may be important to consider how to enable good and meaningful everyday living with less mobility for older people facing mobility difficulties. In our study, the interdependence of older individuals with supportive socio-material surroundings enabled them to age in place with less mobility. This is in line with previous research that showed that assistance from social circles can enable older people to maintain their home (Coleman et al., 2016). Previous research has also brought attention to other ways of compensating for physical mobility loss, e.g. a window with a view can allow older people with mobility restrictions to remain connected with the outside world, as they can observe people, vehicles, clouds and seasons go by (Musselwhite, 2018). Distances can also be reached through imaginative, virtual and communicative travel (Urry, 2002). Although previous research has shown that restricted out-of-home mobility is associated with reduced wellbeing in later life (Rantakokko et al., 2010, 2016), other mobilities (electronic, imaginary and mental) may have the potential to compensate for some of the physical mobility loss (Ziegler and Schwanen, 2011). Virtual travel has already become part of many people's daily lives and is transforming our ideas of co-presence with people, places and events. However, physical travel enables sensing places directly through seeing, touching, hearing and smelling. Hence, an important question is to what extent can virtual travel replace physical travel? (Urry, 2002). Thus, it may be important to study different mobilities and their 'fluid interdependence' (Urry, 2002; Sheller and Urry, 2006: 212; Ziegler and Schwanen, 2011). More research is required to understand how and to what extent supporting daily life with decreased physical mobility can enable good and meaningful daily life for older people facing mobility restrictions.

This study focused on the everyday life perspective of older individuals. The focus groups entailed loosely facilitated discussions regarding participants' daily lives, which has both limitations and strengths. More specific focus on out-of-home mobility could have provided more detailed data on mobility restrictions and possibilities. Nevertheless, allowing participants to share perceptions of their daily lives relatively freely enabled them to bring up issues that were authentically meaningful and important for them. It also enabled scrutinising a wide variety of contextual aspects of out-of-home mobility.

To conclude, our findings show that older people organise their out-of-home mobility and independent living in complex interdependencies with their social networks, built and natural living environments, transport infrastructure, weather conditions and societal arrangements. We suggest that both sides of the coin should be considered in research and policy: how to enable out-of-home mobility for older people facing mobility restrictions and how to support them to manage and enjoy daily life with less mobility if getting out and moving about is not possible. Policies promoting the independent living of older people tend to promote the ideal of selfreliant and active older individuals, although we may face situations in our lives in which we do not fulfil this ideal. This moral context can create barriers for older people in accepting assistance due to fear of being burdensome and may hamper their sense of self when they face restrictions in their daily lives (Portacolone, 2011). Hence, we suggest that, while enhancing the activity and out-of-home mobility of older individuals is a highly valuable goal for both individuals and societies, a more sensitive policy approach would involve appreciating and supporting 
different ways of moving and living in later life. Research focusing on the day-to-day contexts of older people can provide insights into these different ways of living and the complex interdependencies required to organise independent living and out-of-home mobility in later life.

Acknowledgements. We thank researchers in OMAgroup as well as Hilma Halme, Salla Era and Päivi Moisio for valuable comments on draft versions of this article. We also thank the two community centres and the Age-friendly Hervanta project for co-operation in organising the focus groups, and participants for sharing their experiences.

Author contributions. Both authors contributed to all phases of the study and the article, and approved the submission of the article.

Financial support. This work was supported by the Strategic Research Council of Academy of Finland; the research was conducted in the Dwellers in Agile Cities (grant number 303481) and Towards Eco-welfare State research projects (grant number 327161). The funding organisation did not have a role in design, execution, analysis and interpretation of data.

Conflict of interest. The authors declare no conflicts of interest.

Ethical standards. We followed the ethical guidelines of the Finnish National Board on Research Integrity (TENK) and the legislation in Finland. In Finland, an ethical review in human sciences is required only in precisely defined research designs which deviate from TENK's ethical principles. As our study adheres to the ethical principles of TENK, ethical review was not required.

\section{Notes}

1 Act on Supporting the Functional Capacity of the Older Population and on Social and Health Care Services for Older Persons 980/2012, available at https://www.finlex.fi/fi/laki/ajantasa/2012/20120980.

2 Social Welfare Act 1301/2014, available at https://www.finlex.fi/fi/laki/ajantasa/2014/20141301.

3 Act on Disability Services and Assistance 380/1987, available at https:/www.finlex.fi/fi/laki/ajantasa/ 1987/19870380.

4 Public Order Act 612/2003, available at https://www.finlex.fi/fi/laki/ajantasa/2003/20030612.

\section{References}

Aavajoki S (2012) Pyöräilyn ja kävelyn olosuhteet Suomen kaupungeissa (Research Report No. 79). Tampere, Finland: Tampere University of Technology, Transport Research Centre Verne.

Age Institute (nd) Strength in Old Age Programme. Helsinki: Age Institute. Available at https://www. voimaavanhuuteen.fi/en/.

Anttonen A and Häikiö L (2011) From social citizenship to active citizenship? Tensions between policies and practices in Finnish elderly care. In Newman J and Tonkens E (eds), Participation, Responsibility and Choice: Summoning the Active Citizen in Western European Welfare States. Amsterdam: Amsterdam University Press, pp. 67-86.

Bland R (1999) Independence, privacy and risk: two contrasting approaches to residential care for older people. Ageing \& Society 19, 539-560.

Capaldi CA, Passmore H-A, Nisbet EK, Zelenski JM and Dopko RL (2015) Flourishing in nature: a review of the benefits of connecting with nature and its applications as a wellbeing intervention. International Journal of Wellbeing 5, 1-16.

City of Tampere (nd) Väestö ja väestönmuutokset. Tampere, Finland: City of Tampere. Available at https:// www.tampere.fi/tampereen-kaupunki/tietoa-tampereesta/tietonakoala/vaesto-ja-vaestonmuutokset.html.

Clark-Ibáñez M (2004) Framing the social world with photo-elicitation interviews. American Behavioral Scientist 47, 1507-1527. 
Clarke PJ (2014) The role of the built environment and assistive devices for outdoor mobility in later life. Journals of Gerontology: Psychological Sciences and Social Sciences 69B, S8-S15.

Clarke P and Gallagher NA (2013) Optimizing mobility in later life: the role of the urban built environment for older adults aging in place. Journal of Urban Health 90, 997-1009.

Clarke P, Hirsch J, Melendez R, Winters M, Sims Gould J, Ashe M, Furst S and McKay H (2017) Snow and rain modify neighbourhood walkability for older adults. Canadian Journal of Ageing 36, 159-169.

Coleman T, Kearns RA and Wiles J (2016) Older adults' experiences of home maintenance issues and opportunities to maintain ageing in place. Housing Studies 31, 964-983.

Collopy BJ (1995) Power, paternalism and the ambiguities of autonomy. In Gamroth LM, Semradek J and Tornquist EM (eds), Enhancing Autonomy in Long-term Care. Concepts and Strategies. New York, NY: Springer, pp. 3-14.

Engels B and Liu GJ (2013) Ageing in place: the out-of-home travel patterns of seniors in Victoria and its policy implications. Urban Policy and Research 31, 168-189.

Fine $\mathbf{M}$ and Glendinning C (2005) Dependence, independence or inter-dependence? Revisiting the concepts of 'care' and 'dependency'. Ageing \& Society 25, 601-621.

Finlay J, Franke T, McKay H and Sims-Gould J (2015) Therapeutic landscapes and wellbeing in later life: impacts of blue and green spaces for older adults. Health \& Place 34, 97-106.

Föbker S and Grotz R (2006) Everyday mobility of elderly people in different urban settings: the example of the city of Bonn, Germany. Urban Studies 43, 99-118.

Franke T, Winters M, McKay H, Chaudhury H and Sims-Gould J (2017) A grounded visualization approach to explore sociospatial and temporal complexities of older adults' mobility. Social Science \& Medicine 193, 59-69.

Franke T, Sims-Gould J, Habib C, Winters M and McKay H (2019) 'It makes your life worthwhile. It gives you a purpose in living': mobility experiences among active older adults with low income. Ageing \& Society 39, 1639-1666.

Franke T, Sims-Gould J, Chaudhury H, Winters M and McKay H (20) ) Re-framing mobility in older adults: an adapted comprehensive conceptual framework. Qualitative Research in Sport, Exercise and Health 12, 1-14.

Gale CR, Cooper C and Aihie Sayer A (2014) Prevalence of frailty and disability: findings from the English Longitudinal Study of Ageing. Age and Ageing 44, 162-165.

Goins RT, Jones J, Schure M, Rosenberg DE, Phelan EA, Dodson S and Jones DL (2015) Older adults' perceptions of mobility: a metasynthesis of qualitative studies. The Gerontologist 55, 929-942.

Graham H, de Bell S, Flemming K, Sowden A, White P and Wright K (2020) Older people's experiences of everyday travel in the urban environment: a thematic synthesis of qualitative studies in the United Kingdom. Ageing \& Society 40, 842-868.

Green J, Jones A and Roberts H (2014) More than A to B: the role of free bus travel for the mobility and wellbeing of older citizens in London. Ageing \& Society 34, 472-494.

Hallgrimsdottir B and Ståhl A (2018) The impact of measures taken in the outdoor environment on an ageing population: a panel study over a ten-year period. Ageing \& Society 38, 217-239.

Jolanki OH (2009) Agency in talk about old age and health. Journal of Aging Studies 23, 215-226.

King MD, Meuser TM, Berg-Weger M, Chibnall JT, Harmon AC and Yakimo R (2011) Decoding the Miss Daisy Syndrome: an examination of subjective responses to mobility change. Journal of Gerontological Social Work 54, 29-52.

Kröger T and Bagnato A (2017) Care for older people in early twenty-first-century Europe: dimensions and directions of change. In Martinelli F, Anttonen A and Mätzke M (eds), Social Services Disrupted. Changes, Challenges and Policy Implications for Europe in Times of Austerity. Cheltenham, UK: Edward Elgar Publishing, pp. 201-218.

Kröger T and Leinonen A (2012) Transformation by stealth: the retargeting of home care services in Finland. Health and Social Care in the Community 20, 319-327.

Kröger T, Puthenparambil JB and Van Aerschot L (2019) Care poverty: unmet care needs in a Nordic welfare state. International Journal of Care and Caring 3, 485-500.

Landauer M, Haider W and Pröbstl-Haider U (2013) The influence of culture on climate change adaptation strategies: preferences of cross-country skiers in Austria and Finland. Journal of Travel Research 53, 96-110.

Moisio P and Savolainen-Korjus E (2018) Kohti ikäystävällisempää Hervantaa. Ministry of the Environment. Available at http://julkaisut.valtioneuvosto.fi/handle/10024/160490. 
Mollenkopf H (2005) The significance of out-of-home mobility in modern society. In Mollenkopf $\mathrm{H}$, Marcellini F, Ruoppila I, Széman Z and Tacken M (eds), Enhancing Mobility in Later Life. Personal Coping, Environmental Resources and Technical Support. The Out-of-home Mobility of Older Adults in Urban and Rural Regions of Five European Countries. Amsterdam: IOS Press, pp. 1-9.

Mollenkopf H, Marcellini F, Ruoppila I, Széman Z, Tacken M, Kaspar R and Wahl H-W (2002) The role of driving in maintaining mobility in later life: a European view. Gerontechnology 2, 231-250.

Mollenkopf H, Marcellini F, Ruoppila I, Széman Z, Tacken M and Wahl H-W (2004) Social and behavioural science perspectives on out-of-home mobility in later life: findings from the European project MOBILATE. European Journal of Ageing 1, 45-53.

Mollenkopf H, Hieber A and Wahl H-W (2011) Continuity and change in older adults' perceptions of out-of-home mobility over ten years: a qualitative-quantitative approach. Ageing \& Society 31, 782-802.

Morgan DL (2001) Focus group interviewing. In Gubrium JF and Holstein JA (eds), Handbook of Interview Research. Context \& Method. Thousand Oaks, CA: Sage, pp. 141-159.

Musselwhite C (2017) Exploring the importance of discretionary mobility in later life. Working with Older People 21, 49-58.

Musselwhite C (2018) The importance of a room with a view for older people with limited mobility. Quality in Ageing and Older Adults 19, 273-285.

Musselwhite C and Haddad H (2010) Mobility, accessibility and quality of later life. Quality in Ageing and Older Adults 11, 25-37.

Nordbakke S (2013) Capabilities for mobility among urban older women: barriers, strategies and options. Journal of Transport Geography 26, 166-174.

Nowell LS, Norris JM, White DE and Moules NJ (2017) Thematic analysis: striving to meet the trustworthiness criteria. International Journal of Qualitative Methods 16, 1-13.

Official Statistics of Finland (nd) Population. Helsinki: Statistics Finland. Available at https://www.stat.fi/ til/vrm_en.html.

Pirhonen J, Ojala H, Lumme-Sandt K and Pietilä I (2016) 'Old but not that old': Finnish community-dwelling people aged 90+ negotiating their autonomy. Ageing \& Society 36, 1625-1644.

Plath D (2008) Independence in old age: the route to social exclusion? British Journal of Social Work 38, 1353-1369.

Portacolone E (2011) The myth of independence for older Americans living alone in the Bay Area of San Francisco: a critical reflection. Ageing \& Society 31, 803-828.

Portegijs E, Rantakokko M, Mikkola TM, Viljanen A and Rantanen T (2014) Association between physical performance and sense of autonomy in outdoor activities and life-space mobility in community-dwelling older people. Journal of the American Geriatrics Society 62, 615-621.

Rantakokko M, Iwarsson S, Kauppinen M, Leinonen R, Heikkinen E and Rantanen T (2010) Quality of life and barriers in the urban outdoor environment in old age. Journal of the American Geriatrics Society 58, 2154-2159.

Rantakokko M, Iwarsson S, Portegijs E, Viljanen A and Rantanen T (2015) Associations between environmental characteristics and life-space mobility in community-dwelling older people. Journal of Aging and Health 27, 606-621.

Rantakokko M, Portegijs E, Viljanen A, Iwarsson S, Kauppinen M and Rantanen T (2016) Changes in life-space mobility and quality of life among community-dwelling older people: a 2-year follow-up study. Quality of Life Research 25, 1189-1197.

Reindal SM (1999) Independence, dependence, interdependence: some reflections on the subject and personal autonomy. Disability \& Society 14, 353-367.

Rosenberg DE, Huang DL, Simonovich SD and Belza B (2013) Outdoor built environment barriers and facilitators to activity among midlife and older adults with mobility disabilities. The Gerontologist 53, 268-279.

Rosso AL, Auchincloss AH and Michael YL (2011) The urban built environment and mobility in older adults: a comprehensive review. Journal of Aging Research 2011, 816106.

Saarnio R and Isola A (2010) Nursing staff perceptions of the use of physical restraint in institutional care of older people in Finland. Journal of Clinical Nursing 19, 3197-3207.

Satariano WA, Kealey M, Hubbard A, Kurtovich E, Ivey SL, Bayles CM, Hunter RH and Prohaska TR (2016) Mobility disability in older adults: at the intersection of people and places. The Gerontologist 56, $525-534$. 
Schwanen T and Páez A (2010) The mobility of older people: an introduction. Journal of Transport Geography 18, 591-595.

Schwanen T and Ziegler F (2011) Wellbeing, independence and mobility: an introduction. Ageing \& Society 31, 719-733.

Schwanen T, Banister D and Bowling A (2012) Independence and mobility in later life. Geoforum 43, 1313-1322.

Secker J, Hill R, Villeneau L and Parkman S (2003) Promoting independence: but promoting what and how? Ageing \& Society 23, 375-391.

Sheller M and Urry J (2006) The new mobilities paradigm. Environment and Planning A: Economy and Space 38, 207-226.

Shumway-Cook A, Ciol MA, Yorkston KM, Hoffman JM and Chan L (2005) Mobility limitations in the medicare population: prevalence and sociodemographic and clinical correlates. Journal of the American Geriatrics Society 53, 1217-1221.

Sievänen T and Neuvonen M (2010) Luonnon virkistyskäyttö 2010. Finnish Forest Research Institute, Vantaa, Finland, Working Paper 212. Available at https://jukuri.luke.fi/handle/10024/536119.

Smith AR, Chen C, Clarke P and Gallagher NA (2016) Trajectories of outdoor mobility in vulnerable elderly: the role of individual and environmental factors. Journal of Aging and Health 28, 796-811.

Su F (2007) Understanding and Satisfying Older People's Travel Demand ( $\mathrm{PhD}$ thesis). Imperial College London, London.

Su F and Bell MGH (2009) Transport for older people: characteristics and solutions. Research in Transportation Economics 25, 46-55.

TENK (nd) Ethical Review in Human Sciences. Ethical Principles in the Humanities and Social and Behavioural Sciences. Available at https://www.tenk.fi/en/ethical-review-in-human-sciences.

Tiilikainen E, Hujala A, Kannasoja S, Rissanen S and Närhi K (2019) 'They're always in a hurry' - older people's perceptions of access and recognition in health and social care services. Health and Social Care in the Community 27, 1011-1018.

Tuominen K and Pirhonen J (2019) 'Who would take a 90-year-old?' Community-dwelling nonagenarians' perceptions of social relationships. International Journal of Ageing and Later Life 13, 111-137.

Urry J (2002) Mobility and proximity. Sociology 36, 255-274.

Webber SC, Porter MM and Menec VH (2010) Mobility in older adults: a comprehensive framework. The Gerontologist 50, 443-450.

Wennberg H, Ståhl A and Hydén C (2009) Older pedestrians' perceptions of the outdoor environment in a year-round perspective. European Journal of Ageing 6, 277-290.

Wilkie R, Peat G, Thomas E and Croft P (2006) The prevalence of person-perceived participation restriction in community-dwelling older adults. Quality of Life Research 15, 1471-1479.

Ziegler F and Schwanen T (2011) 'I like to go out to be energised by different people': an exploratory analysis of mobility and wellbeing in later life. Ageing \& Society 31, 758-781.

Cite this article: Luoma-Halkola H, Häikiö L (2022). Independent living with mobility restrictions: older people's perceptions of their out-of-home mobility. Ageing \& Society 42, 249-270. https://doi.org/10.1017/ S0144686X20000823 